

\section{PAISAGENS \\ DA SERRA DO \\ ESPINHAÇO}

PAULO BAPTISTA*:

PalaVras-chave Paisagem. Fotografia. Preservação ambiental.

\section{LANDSCAPES OF THE ESPINHAÇO RIDGE}

KEYwORDS Photography. Environmental preservation.

* Professor Adjunto do Departamento de Fotografia, Teatro e Cinema da Escola de Belas Artes da UFMG. Doutor em Artes e pesquisador nas áreas de fotografia, imagem digital, paisagem e preservação ambiental. E-mail: paulobaptista@ufmg.br 

or que fotografar a paisagem? Essa é a pergunta que ouvi mais de uma vez, desde que comecei, em meados dos anos I980, a me aventurar pelos arredores de Belo Horizonte carregando uma câmara de madeira e metal, algumas objetivas, tripé e um suprimento de folhas de filme de grande formato. A resposta, invariavelmente, referiase a uma preocupação pessoal com aqueles lugares, à percepção de que eles estão sujeitos a processos de transformação, muitas vezes determinados por interesses alheios à realidade das populações locais - interesses que frequentemente desconsideram aspectos particulares da sua paisagem, de suas condições socioambientais e tradições culturais em nome de um suposto progresso econômico, procurando repetir no campo um modelo urbano em claro processo de exaustão nas grandes cidades.

Na região da Serra do Espinhaço - a mais longa cadeia de montanhas do Brasil, reconhecida como Reserva Mundial da Biosfera pela UNESCO - encontram-se cidades e povoados localizados em cenários de grande beleza cênica e importância histórica. A cadeia do Espinhaço compreende também amplas extensões de áreas rurais, ainda com pouca ou nenhuma ocupação humana, que apresentam características ambientais extremamente relevantes em termos de paisagem, geomorfologia e biodiversidade; algumas dessas áreas vêm sendo ameaçadas ou sofrendo interferências significativas em seu equilíbrio ambiental há anos, em razão, entre outros fatores, da expansão da ocupação urbana e da implantação de grandes empreendimentos de extrativismo mineral.

As fotografias desta série procuram resgatar, em imagens, um pouco desse riquíssimo patrimônio ambiental e paisagístico, em uma abordagem que espera contribuir para os esforços cada vez mais necessários à sua preservação. 


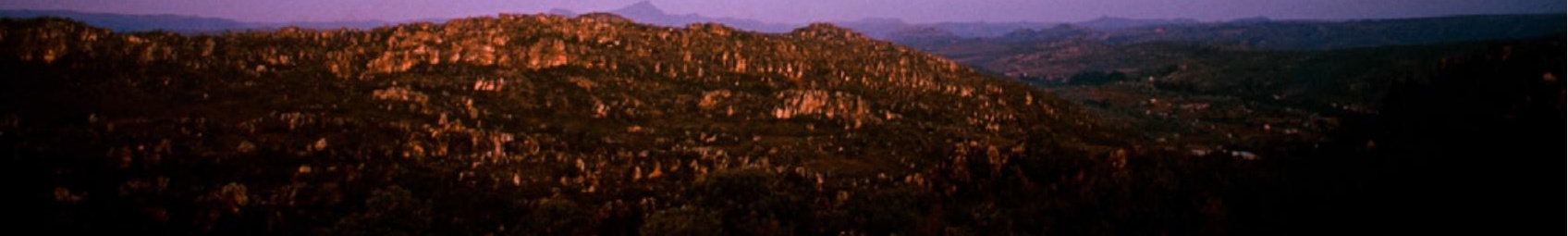

Serra dos Cristais, com o Pico do Itambé ao fundo, Diamantina, 2000

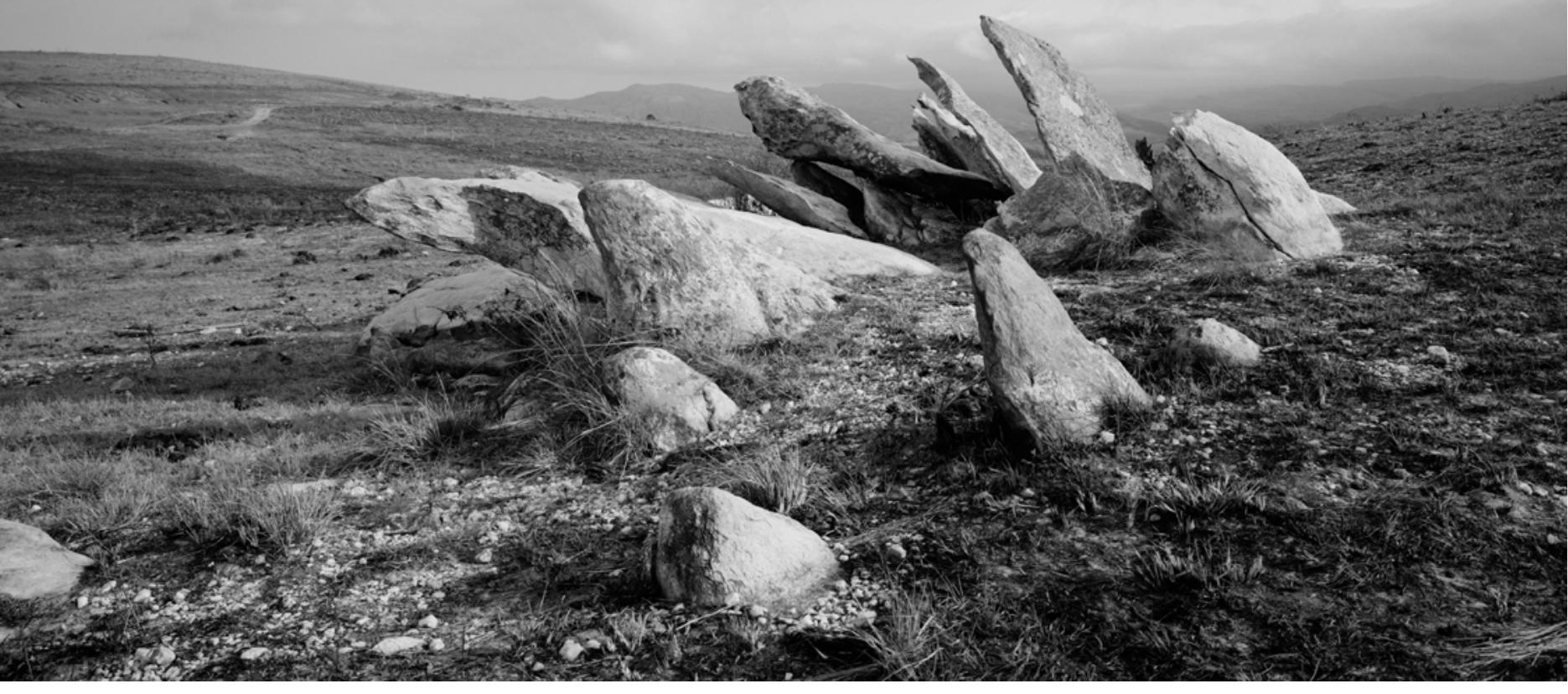

Afloramentos rochosos no caminho do Travessão, Parque Nacional da Serra do Cipó, 1999 




Brejo, vale do Rio

Mascate, Parque

Nacional da Serra do

Cipó, 1996




BAPTISTA, P.

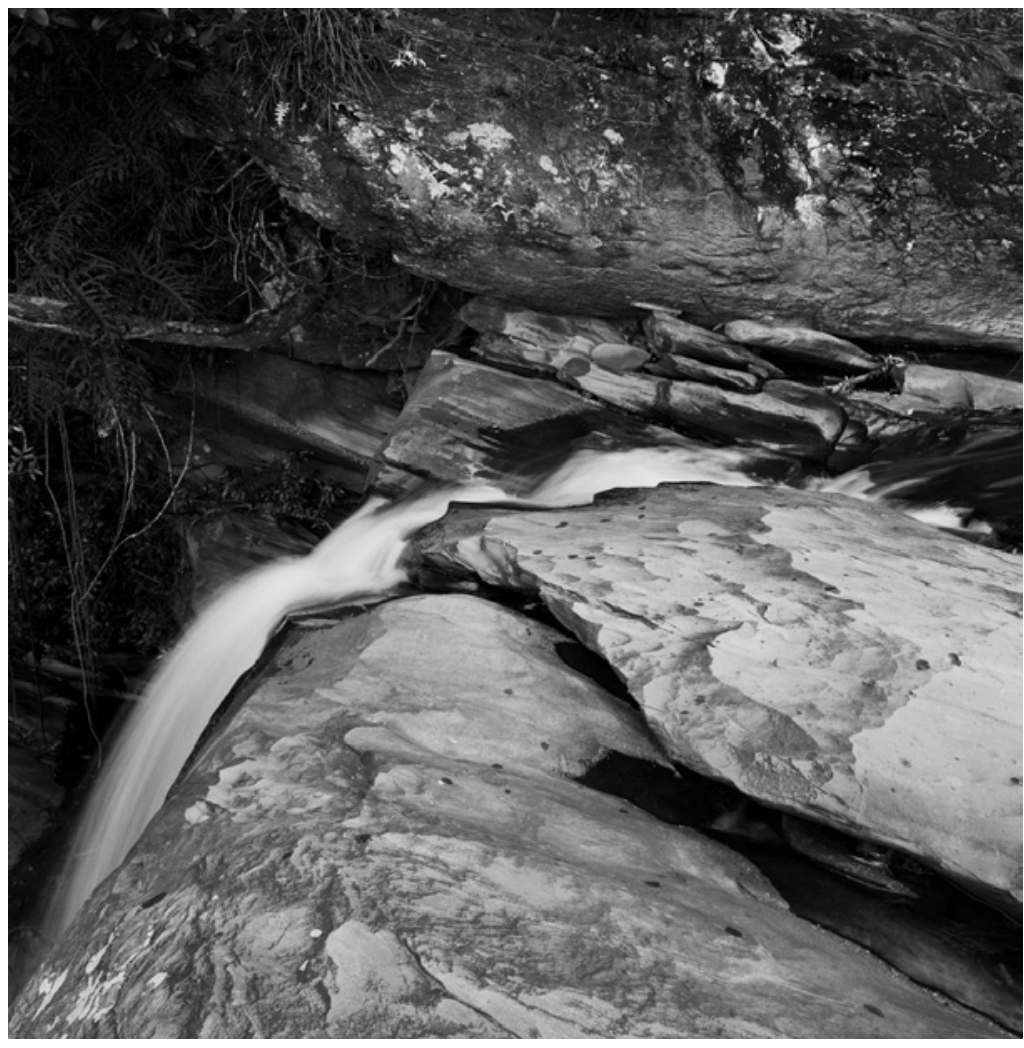

Salto superior da Garganta do Diabo, Ribeirão Cortesia, região da Serra do Gandarela, 1990

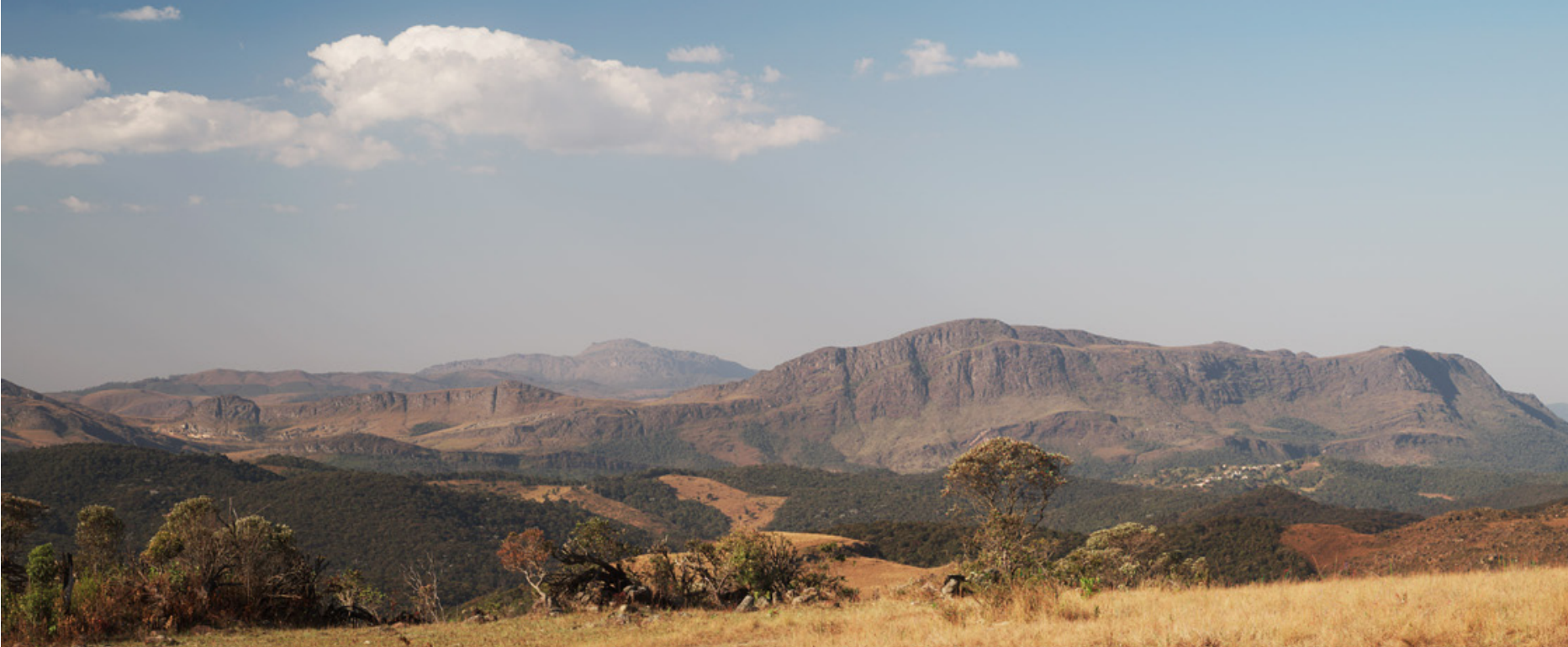

Serra da Chapada vista da Serra de Ouro Branco, com o pico do Itacolomi ao fundo, 2008 